УДК 94

\title{
Э.Э. Шульи
}

\section{НОЯБРЬСКАЯ РЕВОЛЮЦИЯ 1918 Г. В ГЕРМАНИИ И ПРОБЛЕМЫ ВОЗНИКНОВЕНИЯ, РАЗВИТИЯ И ПАДЕНИЯ ВЕЙМАРСКОЙ РЕСПУБЛИКИ}

\begin{abstract}
Рассматривается история Веймарской республики через призму алгоритма Немецкой революции. Сравнительноисторический анализ позволяет выявить общие черты Немецкой революции и Веймарской республики с событиями Великой Французской революции, революции во Франции 1848 г. и революции в России 1917-1922 гг. Автор приходит к выводу, что Веймарская республика стала таким же периодом революционного развития Германии, как и Первая республика во Франции, что обусловило ее историю, многие закономерности ее возникновения, развития и падения.

Ключевые слова: Ноябрьская революция 1918 г.; Веймарская республика; Первая республика.
\end{abstract}

В 2018 г. будет отмечаться 100-летний юбилей революции в Германии и образования Веймарской республики. В связи с этим особую актуальность приобретают ревизия наших знаний об этих событиях, возможный пересмотр подходов и устоявшихся точек зрения. В этой связи большой потенциал лежит в пересмотре датировки Немецкой революции, получившей название Ноябрьской революции 1918 г., но на самом деле «простиравшейся» значительно дальше событий 4-9 ноября и даже 11 августа 1919 г. - день подписания президентом республики Веймарской конституции. Проблема датировки и этапов Немецкой революции лежит глубже простых исторических дат и связана с пониманием социальных и политических процессов в Веймарской республике. Принципиально иные подходы позволяют объяснить короткую и особенную историю Веймарской республики и феномен прихода нацистов к власти в Германии. Подход к датировке и этапности Немецкой революции основан на сравнительном анализе и общетеоретических подходах в этих вопросах применительно ко всем мировым революциям [1. С. 11-68, 93-170].

Напомним события Немецкой революции, так как это поможет провести несколько параллелей.

3 ноября 1918 г. подняли восстание моряки Киля и Вильгельмсхафена, которые не желали больше воевать. Беспорядки охватили всю страну, кайзер Вильгельм II бежал из страны, а лидеры Социалдемократической партии Германии (СДПГ) провозгласили Германию республикой. Однако, как и в России, гражданская война в стране только начинала набирать обороты. 5 января 1919 г. (через два месяца после Ноябрьской революции) в Берлине вспыхнуло восстание, организованное только что возникшей Коммунистической партией Германии (КПГ) и «независимцами» (далее - НСДПГ). Новой власти пришлось подавлять восстания в середине и второй половине января в Берлине, Бремене, Дюссельдорфе, Мюльхайме, Халле и других городах. Однако уже 3 марта в Берлине началась всеобщая забастовка, а 5 марта - уличные бои. И снова вслед за Берлином пришлось подавлять восстания в других немецких городах: Лейпциге, Дрездене, Магдебурге, Брауншвейге - и в Баварии, где целый месяц просуществовала Баварская советская республика. Уже через год в марте 1920 г. - произошел Капповский путч - попытка государственного переворота генералитета, за которой последовали всеобщая забастовка в Берлине и восстание рабочих в Руре. Красная гвардия Рурской области, организованная коммунистами, за 10 дней захватила основные города региона: Дюссельдорф, Эссен, Мюльхайм, Дуйсбург, Хамборн, Кирхеллен, Дорстен, Вольтен, Хальтем, Ольфег, Везель и Хилтуп. В начале апреля правительственным войскам удалось разгромить эти вооруженные части. Еще ровно через год - в марте 1921 г. - произошли новые выступления коммунистов. 22 марта 1921 г. бастующие рабочие вступили в вооруженное столкновение с полицией в Айслебене и Шраплау, а затем в саксонских Хетштедте и Рублингене, а 24 марта КПГ организовала уличные беспорядки в Гамбурге в поддержку восставшей Саксонии. Забастовки рабочих охватили обширный район Саксонии. Войскам рейхсвера пришлось брать город за городом, и только 1 апреля восстание было окончательно подавлено. Через два с половиной года - 23-25 октября 1923 г. - лидер коммунистов Эрнст Тельман поднял восстание в Гамбурге, а 9 ноября в Мюнхене произошел так называемый пивной путч, организованный лидером НСДАП Адольфом Гитлером и генералом Людендорфом. Оба выступления слева и справа, в Гамбурге и Мюнхене, - были быстро подавлены [2. С. 50-52].

Исследователи делят Немецкую революцию на три или четыре этапа. Первый этап - 3-10 ноября 1918 г. от восстания матросов в Киле до создания нового правительства - Совета народных уполномоченных. Второй этап - до январских боев в Берлине в 1919 г. Третий этап - до мая 1919 г. и падения Баварской советской республики или до восстания в Руре в марте 1920 г. [3. С. 72]. К этому можно добавить и период до марта 1921 г. или до ноября 1923 г. с «пивным путчем» в Мюнхене и восстанием коммунистов в Гамбурге. На наш взгляд, периодизации Немецкой революции больше подходит двухэтапный принцип: 1) Ноябрьская революция и провозглашение республики в ноябре 1918 г.; 2) январь 1919 - ноябрь 1923 г. - попытки левых и правых сил совершить «частичный откат» или «продвинуть революцию дальше», т.е. сместить вправо или еще левее. Соответственно, и датировать окончание Немецкой революции точнее ноябрем 1923 г., когда ее дальнейшее движение влево потерпело поражение и в стране закончилась гражданская война (после этих бурных событий социальный протест выплескивался на улицы, приводил к массовым манифестациям, забастовкам и беспорядкам, но не к восстаниям и большим вооруженным 
столкновениям. Этот протест несколько спал в период экономической стабилизации 1926-1928 гг., но снова стал нарастать вместе с мировым экономическим кризисом 1929 г.) [2. С. 72-78, 160-161; 4. С. 80, 84-89].

Общие черты Русской и Немецкой революций бросаются в глаза. Так, революция в России и в Германии и свержение монархии стали результатом поражения в войне и военных тягот. Как и в Русской февральской, Ноябрьскую революцию 1918 г. никто не ждал и не готовил. Как и в Русской революции, все последующие выступления в Германии были спланированы и возглавлены [5. С. 95-140, 195-232]. Ноябрьская революция, как и февральская, произошла в результате забастовок рабочих и выступления ряда воинских частей в поддержку. И в России, и в Германии случился период двоевластия Советов и правительства. Выступления в Германии 1919-1921 гг. сильно походили на события 1917 г. в Петрограде: июльские события, Корниловский мятеж и т.д. Характерная особенность обеих революций заключалась в том, что к власти пришли социалисты - умеренно левые. Таким образом, в отличие от известных до этого революций, не происходило длительное движение революции «справа налево» (если в России вести отсчет только с 1917 г.), а затем в обратном направлении - революция сразу дошла до возможного крайнего левого порога. Однако в России этот предел был пройден большевиками, и революция «забрала дальше влево», а в Германии заняла «линию равновесия», с которой ни правым, ни левым не хватило сил сдвинуть республику.

Примечательно, что Германская революция 1918 1923 гг. была сходна одновременно с Русской революцией в ее февральско-октябрьской части и с Французской революцией 1848 г.: падение доверия к монарху, вооруженное восстание, отречение монарха и его отъезд за рубеж, провозглашение президентской республики. Только в Германии вместо одного «июньского восстания» (январское 1919 г. восстание спартакистов является аналогом июньского восстания во Франции в 1848 г.) последовали новые попытки как «правых», так и «левых» восстаний (1920-23 гг.).

Все революции после Великой французской рассматривались сквозь призму аналогий с событиями 1789-1799 гг., и Великая французская революция считалась и считается парадигмой для последующих революций [6. С. 62-63, 70; 7. Р. 3; 8. Р. 34; 9. Р. 13, 15, 128$]$.

В Германии не было первого этапа ограничения монархии, как во Франции (1789-1792 гг.), и только затем, на втором этапе, производилось свержение монархии. Здесь сыграл роль целый ряд факторов, и в первую очередь, конечно, поражение в войне: воспользовавшись слабостью власти, страна, которая уже имела демократический опыт парламента и даже сильную партию социал-демократов (самую сильную в Европе того времени), а также опыт соседних стран, в своей классической революции «перепрыгнула» первый этап.

Примечательно, что в этой части Немецкая революция находит отклик в Русской революции, в которой потенциально период ВФР 1789-1792 гг. можно сравнить с событиями революции 1905-1907 гг. (с той лишь разницей, что во французском случае победили революционеры, а в русском, на этом этапе, - монархия), но 1917 г., как и в Германии в ноябре 1918 г., начинался тоже сразу свержением монархии.

В Германии не было периода якобинской диктатуры: несколько попыток переворота и удержания власти левыми закончились поражением. Здесь сказались особенности федерализма Германии: если во Франции в 1789-1794 гг. достаточно было взять власть в Париже и диктовать волю всей стране, то в Германии Берлин не играл такой роли, а восстания и захват власти в отдельных землях воспринимались как попытки сепаратизма и позволяли противопоставить восставшим немецкую армию и добровольческие дружины (фрайкоры). Немецкие «якобинцы» проиграли, и период после 1923 г. стал движением революции вправо (что является характеристикой термидора).

Споры о том, являлись ли события $30-х$ гг. ХХ в. в Германии революцией, начались с момента прихода Гитлера к власти и продолжаются по сей день. Кроме признания или непризнания периода нацистов в Германии частью революции, существует и расхождение - считать этот феномен Термидором или Бонапартизмом [10. Р. 100, 105].

Сам Гитлер неоднократно заявлял о своей революционности и повторял, что он лидер национальной революции [11. Р. 237; 12. Р. 81]. К «революции» Гитлера современники относились как к революции против революции, к такому явлению, что «с этих пор в Германии больше не должно было быть никаких революций» [13. С. 354]. Современники связали эти события с философскими идеями «консервативной революции» (политико-философские взгляды в Германии 20-30-х гг. ХХ в.) [14. С. 4-7; 15. С. 61]. Некоторые современники называли это событие «национальной революцией крестьянина» [16. С. 3-4]. Немецкий социолог Роберт Михельс ввел даже специальное понятие «реакционные революции», чтобы квалифицировать такие явления, как нацистское движение в Германии и приход Муссолини к власти в Италии [17. С. 108]. Марксистская историография считала фашистские режимы формой контрреволюции [18. C. 86]. Ряд исследователей называли события в Италии и Германии «негативной революцией» [19. P. 427]. Американский историк Джон Лукач даже считал, что, возможно, Гитлер был самым популярным революционным лидером в истории современного мира [12. Р. 50], а одним из самых популярных подходов стало определение фашизма как «революции справа» [20. Р. 347; 21; 22. Р. 159, 167]. За то, что приход нацистов к власти в Германии можно считать революцией, выступали исследователи теории революции К. Бринтон, П. Загорин, Д. Мейсель [23. Р. 276; 24. Р. 133, 137; 25. Р. 7; 26. Р. 57], а также исследователи германской истории и периода прихода нацистов к власти М. Хаусден, М. Катер и многие другие [11. Р. 238; 27. Р. 2, 190-191; 28].

Марксисты (как коммунисты, так и социалдемократы) однозначно расценивали это явления как контрреволюцию [29. Р. 291]. Позиция, что приход Гитлера к власти был контрреволюционным актом, стала популярна среди различных исследователей $[21,24,30]$. 
Однако контрреволюция есть часть революционного процесса [31]. То есть признание прихода Гитлера к власти и его политики в качестве контрреволюции является составной части немецкой революции.

Сногие эксперты считают, что приход Гитлера к власти не имеет никакого отношения к революции. Так, Эрик Хобсбаум считал, что «никакой “фашистской революции” не было», но «в фашистских движениях имелись революционные элементы, поскольку в них участвовали люди, стремившиеся к коренному преобразованию общества» [32. С. 142].

Ральф Дарендорф справедливо отмечал, что Германия после всех реформ и революций пропустила социальную модернизацию, несмотря на высокий уровень индустриализации и урбанизации. Не смогла это положение изменить и Веймарская республика. Национал-социалисты, против их воли, осуществили социальную революцию [33. Р. 64, 402-438]. Джон Хайден и Джон Фаркууарсон призывали рассматривать рост социальной поддержки нацистов до 1933 г. и их политику после прихода к власти в контексте «продолжающейся немецкой социальной революции XX века» [34. Р. 161]. И здесь исследователи абсолютно правы. После революции 1918 г. не была произведена экспроприация феодальных владений высшей аристократии и имущества царствовавшего дома [15. С. 59; 35. С. 131]. Немецкое общество сохраняло рудименты сословности. И что самое главное - Германия находилась в состоянии сильного социального противостояния между левыми и правыми идеями левыми и правыми путями развития страны.

Как справедливо подметил английский историк Эрик Хобсбаум, «чего действительно достиг националсоциализм, так это радикальной чистки старой имперской верхушки власти и государственных учреждений... Разрушение старой элиты и прежних структур, после войны подкрепленное политикой оккупационных армий западных стран, в конечном итоге позволило обеспечить Федеративную Республику Германию гораздо более прочной основой, чем была у Веймарской республики в 1918-1933 годах» [32. С. 142].

Именно эти последствия определяют указанный период как часть немецкой революции. Безусловно, эти движения слева и справа внешне не очень походили на «классические» из истории Великой французской революции, но история никогда не повторяет себя с полной идентичностью, и более чем столетний промежуток между Великой французской революцией и развитием событий в Германии 20-30-х гг. XX в. изменил и внешние условия, и характер действующих лиц. Однако приход к власти нацистов в 1933 г., по сути, явился логическим продолжением движения революционного процесса в Германии, начавшегося в 1918 г. Революцию 1918 г. можно считать завершившейся с окончанием войны: путь «классической революции» от свержения самодержавия через движение влево с неизбежным откатом вправо к состоянию стабильности и частичному возврату к исходному состоянию [31]. Так, поражение Наполеона в войне привело к реставрации монархии во Франции, что, в свою очередь, вызвало новые революции - 1830 и 1848 гг. и появление Второй республики, а после 1870 г. - и
Третьей. В Германии после Второй мировой войны была восстановлена республиканская форма, и стране не понадобились новые революции по аналогии с французскими.

Важен и другой аспект. Дело не в том, что «за два года революция Гитлера принесла экономический рост, полную занятость, законность и правопорядок, стабильные условия и резкое сокращение преступлений», - как писал Жак Эллюль [36. Р. 199], а в том, что стояло за этим: от Гитлера ожидали социального мира в раздираемой социальным противостоянием стране, и его правительству это удалось [4. С. 75-91; 5. С. 233-266]. Такой феномен в революции называется «Бонапартизм».

Л.Д. Троцкий первым назвал фашистские режимы в Италии и Германии Бонапартизмом [37]. Нацистский режим, режимы Муссолини и Франко, португальская диктатура 1926-1974 гг. имеют сходные черты. Все эти режимы на определенном этапе проводили социально-экономические реформы, которые прямо или косвенно привели к формированию современных обществ. Демократическая составляющая была привнесена с падением этих режимов (с поражением в войне, мирным путем или в результате корректирующей революции). Все они являлись заключительной частью революций. Исключение составляет итальянский вариант, где подходящий по всем характеристикам к Бонапартизму режим Муссолини состоялся минуя революцию.

Итальянский случай полностью напоминает немецкий, только с «пропущенной» революцией в начале века. В обеих странах в 1848 г. вспыхнули восстания, в третьей четверти века наблюдались объединительные процессы. В Германии в 1918 г. произошла революция, отголоски которой завершились в 1923 г. Через десять лет к власти пришли нацисты. В Италии по завершении Первой мировой войны революции не произошло, однако в стране ширился социальный протест, который разделил общество и радикализировал его, что позволило прийти к власти фашистам в ноябре 1922 г., - эти факторы сыграли свою роль на десять лет раньше, чем в Германии. В обеих странах приход к власти ультраправых партий с элементами левой и ультралевой идеологии случился под влиянием страха общества перед левыми и ультралевыми и экономическими проблемами.

Эти режимы, за исключением Германии, были характерны для стран, которые вступили в $\mathrm{XX}$ в. с большими феодальными пережитками, с запущенными экономическими и социальными проблемами (Италия, Испания, Португалия). Запущенность социальных проблем, отсутствие сложившихся демократических структур и социальной базы, способной поддержать и отстаивать эти структуры, привели к такой уродливой форме. Еще одна интересная особенность - диктаторские режимы в XX в., производившие социальные и экономические изменения, показали живучесть и долголетие: Гитлер, Муссолини, Сталин, Франко, Пиночет, режим в Португалии с 1926 по 1974 г. Примечательно, что, кроме итальянского примера, все эти диктатуры были так или иначе связаны с революциями, вернее - с их окончанием. 
Итак, если рассматривать Немецкую революцию как классическую по образцу Великой французской революции, то период истории Германии, называемый «Веймарская республика» рождается и заканчивается вместе с этой революцией, охватывая время от свержения монархии в ноябре 1918 г. до становления бонапартистского режима.

Таким образом, Веймарская республика с точки зрения истории революций аналогична Первой французской республике. Первая республика во Франции стала результатом Великой французской революции и существовала от даты отстранения от власти Людовика XVI 21 сентября 1792 г. до провозглашения империи Наполеоном Бонапартом 18 мая 1804 г. Таким образом, Республика появилась после первого этапа революции - конституционной монархии (17891792 гг.), прошла этапы умеренных, якобинцев, Термидора и прекратила существование в этапе Бонапартизма («бонапартистский режим»). Веймарская республика стала таким же периодом революционного развития Германии, как и Первая республика во Франции, что обусловило ее историю, многие закономерности ее возникновения, развития и падения. Безусловно, алгоритм революций и их влияние на историю государств имеют определенные закономерности, и, возможно, именно в этих процессах следует искать объяснения различным событиям периода этой Первой немецкой республики.

\section{ЛИТЕРАТУРА}

1. Шульц Э.Э. Теория революции: революции и современные цивилизации. М. : ЛЕНАНД, 2016. 400 с.

2. Шульц Э.Э. От Веймарской республики к Третьему рейху: Электоральная история. Германии 1920-х - начала 1930-х гг. М. : ЛЕНАНД, 2016. $272 \mathrm{c}$.

3. Патрушев А.И. Германия в ХХ веке. М. : Дрофа, 2004. 432 с.

4. Шульц Э.Э. «Левый» и «правый» бунт в Германии 1920-30-х гг.: истоки, ход событий, результаты. Барнаул : Издательская группа «Сипресс», 2014. 149 с.

5. Шульц Э.Э. Технологии бунта (Технологии управления радикальными формами социального протеста в политическом контексте). М. : Подольская фабрика офсетной печати, 2014. 512 с.

6. Арендт Х. О революции. М. : Европа, 2011.664 с.

7. Rosenstock-Huessy E. Revolution as a Political Concept // Revolutions: Finished and Unfinished, From Primal to Final / ed. by Paul Caringella, Wayne Cristaudo, Glenn Hughes. Cambridge Scholars Publishing, 2012. P. 1-7.

8. Schrecker J.E. The Chinese Revolution in Historical Perspective. Greenwood Publishing Group, 2004.

9. Selbin E. Revolution, rebellion, resistance: the power of story. London; New York : Zed Books, 2010.

10. Herzberger L. The Structure of Thermidor: Some Case Studies. Xlibris Corporation, 2007. 344 p.

11. Kater M.H. The Nazi Party. A Social Profile of Members and Leaders 1919-1945. Cambridge, Massachusetts : Harvard University Press, 1983. $415 \mathrm{p}$.

12. Lukacs J. The Hitler of History. N.Y. : Vintage Books, 1998. 279 p.

13. Нольте Э. Фашизм в его эпохе / пер. с нем. Новосибирск : Сибирский хронограф, 2001. 568 с.

14. Артамошин С.В. Понятия и позиции консервативной революции: интеллектуальное течение «консервативной революции» в политической жизни Веймарской республики. Брянск, 2011.312 с.

15. Ватлин А.Ю. Германия в ХХ веке. М. : РОССПЭН, 2002. 336 с.

16. Сегалл Я.Е. Очерки экономической политики германского фашизма. М. : Гос. соц.-эк. изд-во, 1934. 106 с.

17. Михельс Р. Демократическая аристократия и аристократическая демократия // Социс. 2000. № 1. С. $107-116$.

18. Красин Ю.А. Революцией устрашенные. Критический очерк буржуазных концепций социальной революции. М. : Политиздат, 1975. $366 \mathrm{c}$.

19. Johari J.C. Contemporary Political Theory: New Dimensions, Basic Concepts and Major Trends. Sterling Publishers Pvt. Ltd, 1987.756 p.

20. Freyer H. Revolution from the Right // The Weimar Republic Sourcebook / ed. by Anton Kaes, Martin Jay, Edward Dimendberg. University of California Press, 1994. P. 347-348.

21. Lapp B. Revolution from the Right: Politics, Class and the Rise of Nazism in Saxony. Brill, 1997. 248 p.

22. Mosse G.L. Masses and Man: Nationalist and Fascist Perceptions of Reality. Wayne State University Press, 1987.362 p.

23. Brinton C. The Anatomy of Revolution. Revised and Expanded Edition. N.Y. : Vintage Books, 1965. 310 p.

24. Meisel J.H. Counter-revolution: how revolutions die. Atherton Press, 1966. 237 p.

25. Zagorin P. Rebels and Rulers, 1500-1600: Volume 1, Agrarian and Urban Rebellions: Society, States, and Early Modern Revolution. Cambridge University Press, 1982. 292 p.

26. Calvert P. Revolution and Counter-Revolution Concepts in the Social Sciences. Milton Keynes : Open University Press, 1990.90 p.

27. Housden M. Hitler. Study of a revolutionary. London ; New York : Routledge, 2000. 220 p.

28. Weber E. Revolution? Counterrevolution? What revolution? // Fascism, a Reader's Guide: Analyses, Interpretations, Bibliography / ed. by Walter Laqueur. University of California Press, 1978. P. 435-468.

29. Dutt R.P. Fascism and Social Revolution. Wildside Press LLC, 2009. 320 p.

30. Taylor S. Germany, 1918-1933: revolution, counter-revolution and the rise of Hitler. Duckworth, $1983.131 \mathrm{p}$.

31. Шульц Э.Э. «Моделирование революций» (к дискуссии о стадиях) // Историческая психология и социология истории. 2015. № 2. C. $158-173$.

32. Хобсбаум Э. Эпоха крайностей: Короткий двадцатый век (1914-1991). М. : Независимая газета, 2004.632 с.

33. Dahrendorf R. Society and Democracy in Germany. New York : Doubleday, 1967. 457 p.

34. Saunders T. Nazism and Social Revolution // Modern Germany Reconsidered: 1870-1945 / ed. by Gordon Martel. Taylor \& Francis, 1992. P. 159-177.

35. Нольте Э. Европейская гражданская война (1917-1945). Национал-социализм и большевизм : пер. с нем. М. : Логос, 2003.527 с.

36. Ellul J. Autopsy of Revolution. N.Y. : Knopf, 1971. 300 p.

37. Троцкий Л.Д. Бонапартизм и фашизм: К характеристике современного положения в Eвpoпе. URL: http://revkom.com/biblioteka/ marxism/trotckii/1934bonapart.htm (дата обращения: 16.07.2015).

Статья представлена научной редакцией «История» 30 сентября 2017 г. 


\section{THE NOVEMBER REVOLUTION OF 1918 IN GERMANY AND PROBLEMS OF EMERGENCE, DEVELOPMENT AND FALLING OF THE WEIMAR REPUBLIC}

Vestnik Tomskogo gosudarstvennogo universiteta - Tomsk State University Journal, 2018, 426, $223-228$.

DOI: $10.17223 / 15617793 / 426 / 27$

Eduard E. Shults, Center of Political and Social Technologies (Moscow, Russian Federation). E-mail: nuap1@yandex.ru Keywords: November Revolution of 1918; Weimar Republic; First Republic.

The article aims to consider the history of the Weimar Republic through the prism of the algorithm of the German revolution (that began in November, 1918 and is known as the November Revolution) and its continuation that discloses regularities of the origin, development and disappearance of the first German democracy. A comparative-historical approach to the German revolution (1918-1923), the Great French revolution (1789-1799), the French revolution of 1848, the Russian revolution (1917-1922), the events of the Italian history of the period of Mussolini, the Spanish Franco's period, the Portuguese history from 1926 to 1974 has become the cornerstone of the analysis. The author divides the German revolution into three stages: 1918-1923, 1924-1929, 193033. The first stage lasted from the revolt in Kiel (November 3-10, 1918) to the "beer putsch" in Munich and the revolt of communists in Hamburg in November, 1923. The open civil war in the country ended at that stage: the social protest splashed out in the streets, led to mass demonstrations, strikes and disorders, but not to revolts and big armed conflicts. This protest fell down during the economic stabilization of 1926-1928, but it began to rise again with the world economic crisis of 1929. The second stage (1924-1929) came to an end with the beginning of the world economic crisis. The third stage was connected with the new aggravation of opposition in the German society which led to the polarization and radicalization of society and, eventually, to the rise of the Nazis to power. The analysis shows that the German revolution has common features with the French revolution of 1848 and the Russian revolution in its February-October stage. Besides, the German revolution of 1918-1923 and the subsequent history of the Weimar Republic has broad analogies with the Great French and Russian revolutions in the stages known as the Thermidor and the Bonapartist regime. The author comes to a conclusion that events of the end of 1923 in Germany can be regarded as the Thermidor - a kickback of the revolution to the right, and Hitler's coming to power could be qualified as the Bonapartist regime. This period of the German history finds analogies in contemporary events: the Italian history of the period of Mussolini, Spain in Franco's period, the Portuguese history from 1926 to 1974. The author comes to a conclusion that the Weimar Republic became the same period of revolutionary development of Germany as the First Republic in France, which caused its history, many regularities of its emergence, development and falling.

\section{REFERENCES}

1. Shul'ts, E.E. (2016) Teoriya revolyutsii: revolyutsii i sovremennye tsivilizatsii [The theory of revolution: revolutions and modern civilizations]. Moscow: LENAND.

2. Shul'ts, E.E. (2016) Ot Veymarskoy respubliki $k$ Tret'emu reykhu: Elektoral'naya istoriya Germanii 1920-kh - nachala 1930-kh gg. [From the Weimar Republic to the Third Reich: Electoral history of Germany of the 1920s - early 1930s]. Moscow: LENAND.

3. Patrushev, A.I. (2004) Germaniya v XX veke [Germany in the 20th century]. Moscow: Drofa.

4. Shul'ts, E.E. (2014) "Levyy" $i$ "pravyy" bunt v Germanii 1920-30-kh gg.: istoki, khod sobytiy, rezul'taty [The "left" and "right" rebellions in Germany of the 1920s-1930s: origins, the course of events, results]. Barnaul: Izdatel'skaya gruppa "Si-press"s.

5. Shul'ts, E.E. (2014) Tekhnologii bunta (Tekhnologii upravleniya radikal'nymi formami sotsial'nogo protesta v politicheskom kontekste) [Technology of rebellion (Technology management of radical forms of social protest in a political context)]. Moscow: Podol'skaya fabrika ofsetnoy pechati.

6. Arendt, H. (2011) O revolyutsii [On revolution]. Moscow: Evropa.

7. Rosenstock-Huessy, E. (2012) Revolution as a Political Concept. In: Caringella, P., Cristaudo, W. \& Hughes, G. (eds) Revolutions: Finished and Unfinished, From Primal to Final. Cambridge Scholars Publishing.

8. Schrecker, J.E. (2004) The Chinese Revolution in Historical Perspective. Greenwood Publishing Group.

9. Selbin, E. (2010) Revolution, rebellion, resistance: the power of story. London; New York: Zed Books.

10. Herzberger, L. (2007) The Structure of Thermidor: Some Case Studies. Xlibris Corporation.

11. Kater, M.H. (1983) The Nazi Party. A Social Profile of Members and Leaders 1919-1945. Cambridge, Massachusetts: Harvard University Press.

12. Lukacs, J. (1998) The Hitler of History. N.Y.: Vintage Books.

13. Nolte, E. (2001) Fashizm v ego epokhe [Fascism in its era]. Translated from Germany. Novosibirsk: Sibirskiy khronograf.

14. Artamoshin, S.V. (2011) Ponyatiya i pozitsii konservativnoy revolyutsii: intellektual'noe techenie "konservativnoy revolyutsii" $v$ politicheskoy zhizni Veymarskoy respubliki [Concepts and positions of the conservative revolution: the intellectual direction of the "conservative revolution" in the political life of the Weimar Republic]. Bryansk: Bryanskoe SRP VOG.

15. Vatlin, A.Yu. (2002) Germaniya v XX veke [Germany in the 20th century]. Moscow: ROSSPEN.

16. Segall, Ya.E. (1934) Ocherki ekonomicheskoy politiki germanskogo fashizma [Essays on the economic policy of German fascism]. Moscow: Gos. sots.-ek. izd-vo.

17. Michels, R. (2000) Demokraticheskaya aristokratiya i aristokraticheskaya demokratiya [Democratic aristocracy and aristocratic democracy]. Sotsis - Sociological Studies. 1. pp. 107-116.

18. Krasin, Yu.A. (1975) Revolyutsiey ustrashennye. Kriticheskiy ocherk burzhuaznykh kontseptsiy sotsial'noy revolyutsii [Frightened by the revolution. A critical essay on the bourgeois concepts of social revolution]. Moscow: Politizdat.

19. Johari, J.C. (1987) Contemporary Political Theory: New Dimensions, Basic Concepts and Major Trends. Sterling Publishers Pvt. Ltd.

20. Freyer, H. (1994) Revolution from the Right. In: Kaes, A., Jay, M. \& Dimendberg, E. (eds) (1994) The Weimar Republic Sourcebook. University of California Press.

21. Lapp, B. (1997) Revolution from the Right: Politics, Class and the Rise of Nazism in Saxony. Brill.

22. Mosse, G.L. (1987) Masses and Man: Nationalist and Fascist Perceptions of Reality. Wayne State University Press.

23. Brinton, S. (1965) The Anatomy of Revolution. Revised and Expanded Edition. N.Y.: Vintage Books.

24. Meisel, J.H. (1966) Counter-revolution: how revolutions die. Atherton Press.

25. Zagorin, P. (1982) Rebels and Rulers, 1500-1600: Volume 1, Agrarian and Urban Rebellions: Society, States, and Early Modern Revolution. Cambridge University Press.

26. Calvert, P. (1990) Revolution and Counter-Revolution Concepts in the Social Sciences. Milton Keynes: Open University Press.

27. Housden, M. (2000) Hitler. Study of a revolutionary. London; New York: Routledge.

28. Weber, E. (1978) Revolution? Counterrevolution? What revolution? In: Laqueur, W. (ed.) Fascism, a Reader's Guide: Analyses, Interpretations, Bibliography. University of California Press. 
29. Dutt, R.P. (2009) Fascism and Social Revolution. Wildside Press LLC.

30. Taylor, S. (1983) Germany, 1918-1933: revolution, counter-revolution and the rise of Hitler. London: Duckworth.

31. Shul'ts, E.E. (2015) "Modelirovanie revolyutsiy" (k diskussii o stadiyakh) ["Modeling revolutions" (to the discussion about stages)]. Istoricheskaya psikhologiya i sotsiologiya istorii. 2. pp. 158-173.

32. Hobsbawm, E. (2004) Epokha kraynostey: Korotkiy dvadtsatyy vek (1914-1991) [The Epoch of Extremes: The Short Twentieth Century (19141991)]. Moscow: Nezavisimaya gazeta.

33. Dahrendorf, R. (1967) Society and Democracy in Germany. N.Y.: Doubleday.

34. Saunders, T. (1992) Nazism and Social Revolution. In: Martel, G. (ed.) Modern Germany Reconsidered: 1870-1945. Taylor \& Francis.

35. Nolte, E. (2003) Evropeyskaya grazhdanskaya voyna (1917-1945). Natsional-sotsializm i bol'shevizm [The European Civil War (1917-1945). National Socialism and Bolshevism]. Translated from German. Moscow: Logos.

36. Ellul, J. (1971) Autopsy of Revolution. N.Y.: Knopf.

37. Trotskiy, L.D. (1934) Bonapartizm i fashizm: K kharakteristike sovremennogo polozheniya v Evrope [Bonapartism and Fascism: on the characterization of the current situation in Europe]. [Online] Available from: http://revkom.com/biblioteka/marxism/trotckii/1934bonapart.htm. (Accessed: 16.07.2015).

Received: 30 September 2017 